\title{
The Creation of Interactive Environment for Teachers and Students Teaching under the Condition of Information Technology
}

\author{
Chunxiao Lu \\ Department of Political Theory Teaching, Nanyang Institute of Technology, Nanyang, China \\ 253414574@qq.com
}

\section{Keywords: Information technology; Teaching interaction; Environment}

\begin{abstract}
The behavior of teaching interaction between teachers and students can affect teachers' acceptability and students' participation directly, which is an important factor of the teaching effect. Under the condition of information technology, it is very important to create an educational environment which can guide students to participate and interact actively. The interactive environment of teachers and students teaching includes hardware environment and software environment. The hardware environment can be created from the layout of the classroom, the arrangement of seats, the number of students and so on, as well as the soft environment of interaction between teachers and students can be created from the perspective of the concept, such as changing ideas, respecting students, creating the atmosphere and so on.
\end{abstract}

\section{Introduction}

Since 1990s, the information technology wave which symbolizes by the wide application of computer technology and popularization of the Internet sweeped the globe, rapidly changed the way of production, life and thinking of man, but also affected the way of people's education and learning. In the catalysis of information technology, an educational revolution which has penetrated into all aspects of education and teaching is quietly rising. However, in teaching, whether the transformation of educational thought or the reform of teaching content and teaching methods all need rely on the interaction between teachers and students teaching activities to achieve educational goals ultimately. Teaching interaction has become one of the most basic characteristics of teaching activities, to a certain extent, reflects the nature of teaching.

\section{The Meaning of Teaching Interaction}

Interaction was originally a sociological term, and later was introduced into the field of education. From an educational point of view, interaction is called interaction. Interaction develops in the teaching process between teachers and students to complete the teaching task of teaching and learning in a certain teaching environment, and then becoming exchanges, exchanges, communication, communication, influence and interaction relationship, and teaching content is its media[1]. Under the information technology condition, the teaching interaction presents the following characteristic [2]: (1) Technical. Informationalized classes change the traditional single teaching information transfer mode in which teachers speak only and students listen only. And the teachers can impart teaching information to the students through a variety of modern teaching media, and students can also communicate with teacher through the teaching media, and teaching media is bidirectional information flow through the intermediary. At the same time, the teaching media itself also has the interaction, when teachers and students use the teaching media to work or study, the information will form the interaction between people. (2) Subjectivity. By altering the one-way flow of information in the information technology classroom, students can effectively participate in class interaction, and become the masters of the class, which helps form an equal and democratic relationship between students and students and between students and teachers, and then realize the two-way information transmission between teachers and students. (3) Openness. It is not confined to the fixed closed class teaching mode, but the classroom is extended to the outside class and also extended from the individual learning to the social study. (4) Diversity. With the wide application of multimedia technology, the teaching information in the information class includes 
text, graphics, images, audio, video, animation and other forms of visual stimulation to the students.

\section{The Creation of Interactive Environment for Teaching and Learning}

The implementation of teaching interaction should not only grasp the basic cultural background and discourse rules, but also create a suitable environment for the specific teaching interaction. The creation of specific interactive environment is an indispensable condition to reflect the interaction spirit and to promote interaction.

The Creation of the Hardware Environment. DELL (Dahlke, H.O.) has said: teaching activities in a certain physical environment, which restricts the possibility of students' learning and development in some ways. The physical environment mentioned here refers to the hardware environment in the classroom. Classroom hard ware environment mainly includes the arrangement of the classroom, the arrangement of seats and the number of students.

The first, the desks and chairs arrangement: seat position, to a certain extent, affects a student whether to participate in classroom activities and the degree of participation. The relationship between the tables and chairs and the teaching effect of the scholars have been studied. Effect of hurt (hurt, H.T.) had space on the intercourse between teachers and students in three types for comparison: one is traditional space form, that is, we usually called nursery; the second is horseshoe type space structure; the third is packet type space structure. The results show that the different space is not the same as students' participation in classroom interaction. The classroom teaching in primary and middle schools in China's space is almost the same type of field. Type seedling and seating arrangement reflects the take the teacher as the center of the idea, teachers in the front of the classroom, students for teachers, and their attention as far as possible focus on teachers in the central point, suggesting that the students sitting quietly listening. Composition [3] this space not only in space limits the teacher-student interaction, but also to pass a psychological suggestion, namely teachers and students could not have equal status, students are always passive. Therefore, teachers can try to change seat structure of nursery, according to local conditions, the horseshoe type, block type, umbrella type, such as a variety of layout patterns, so that both can increase teachers and students between more visual and non language communication opportunity, and let every student learn in the interactive experience of success and happiness.

The second, class number: At present, our country's primary and secondary schools are generally the class preparation seriously overweight, six, seventy people's classes are everywhere. The class size is too big is a realistic problem that influences the teaching interaction. As the class size is large, the frequency of interaction between teachers and students will decrease in the unit time. Because in the fixed time, teachers find it difficult to take care of every student in class, give the opportunity to each student interaction, resulting in class some students by teachers' attention and stimulate learning motivation, another part of the students due to lack of equal treatment and lose confidence in learning, which leads to inequality of opportunity for academic success. Therefore, it is necessary to maintain appropriate class size for teachers and students. Small class teaching can not only make the teachers pay attention to all the students in the limited space, but also make every student get the maximum development.

The Creation of Software Environment. Software environment mainly refers to the thoughts, emotions, attitudes, spirits, atmosphere, habits and norms of the interaction between teachers and students. Effect of soft environment for students is unconscious of, that is, through the hint, charisma, empathy, identity, imitation, and the influence of form and gradually make the students' psychological quality change, achieve the conventional teaching can achieve the effect .

The first, change the concept: to deepen the understanding of teaching interaction. In order to realize the positive and effective interaction between teachers and students, to promote the all-round development of students, teachers must change their ideas. First of all, we should establish a new concept of students. In teaching activities, teachers should regard students as the life consciousness of people, need to understand the need to respect, more need to guide people. In addition, the students are no longer passive learners and filling knowledge containers, but active learners and construction. Performance in learning attitude, not only book, not only Division, not however, "rumba, my love truth more" has become the pursuit of the consciousness of students. Secondly, 
establish a new concept of teachers. The construction of teachers in information era, the role should be knowledge teaching to students' learning facilitator and significance of excitation transformation, namely the role of the teacher is from "teaching" to "guide" the transformation. Third, establish a new media view. The use of information technology in the classroom teaching, optimize the teaching means, change the teaching form, this is a major change and innovation in the classroom teaching mode. Finally, establish a new evaluation concept. For students' evaluation, it is not only to pay attention to the students' understanding and mastering of knowledge and skills, but also pay attention to the formation and development of their emotions and attitudes.

The second, respect for students: the establishment of a harmonious relationship between teachers and students. The harmonious relationship between teachers and students is a good guarantee for the normal teaching order and learning environment, as well as the premise of effective interaction between teachers and students. Shelf to create an equal and harmonious relationship between teachers and students, teachers must adhere to the democratic and equal education style, positioning itself to and students equal participants in learning, cooperation and guidance, the students as the main body of the independent personality, establish student in education process should be the dominant position, put down the dignity of the teaching profession, humbly listen to students' understanding of the text, and respect the students point of view, willing to accept students have different opinions, dare to doubt their own point of view, resulting in equal exchanges with students ideas collide with each other, inspire each other, mutual acceptance, mutual integration, to knowledge and spirit of the co construction of syngeneic.

The last, the creation of situations: to create a relaxed and harmonious classroom atmosphere. Interaction context is the specific environment when the interaction is carried out. It is the interactive situation that the teachers and students mind communication, the students both experience and to explore and solve the new problems related to the student's sense of reason and emotion [4]. Safe, pleasant, relaxed external environment is the basic premise for the construction of active and effective interaction. The teacher can gave a gentle eye, a knowing smile, a warm heart words, a praise of attitude, a thoughtful action to achieve. All of these will make the students feel the teacher's care and the recognition, in the psychological will produce a kind of pleasure and satisfaction. Obviously, the emotional communication between teachers and students and the resulting psychological atmosphere will undoubtedly provide the necessary conditions for effective interaction between teachers and students. Finally, teachers should be good at controlling their emotions, don't put their own negative emotions into the classroom, should always full of enthusiasm and positive attitude to face the students, and be good at regulating the learning atmosphere in the classroom of middle school students, towards the positive, enthusiastic and full of vitality in the direction of the development.

\section{References}

[1] C.P.Li. Education Theory and Practice, (2008) Vol.7, p.40.

[2] J.Tian, et al. Modern Educational Science, (2009) Vol.13, p.24.

[3] G.R.Van. Education ecology (People's Education Press, Beijing 2000).

[4] H.Zhang. Curriculum and teaching theory (Shanghai Education Publishing House, Shanghai 2000). 